To cite this article: Money, R., Wilde, S., \& Dawson, D. (2020). The effectiveness of Theraplay fo $12-a$ systematic literature review. Child and Adolescent Mental Health.

\title{
The effectiveness of Theraplay for children under 12: A systematic literature review
}

Short title: Theraplay Systematic Literature Review

Rebecca Money ${ }^{* 1}$, Dr Sarah Wilde ${ }^{1}$, and Dr Dave Dawson ${ }^{1}$

${ }^{1}$ School of Psychology, Doctorate in Clinical Psychology (DClinPsy), University of Lincoln, UK.

${ }^{*}$ Corresponding author information: Rebecca Money, Trent DClinPsy, University of Lincoln, Sarah Swift Building, Brayford East, Lincoln, Lincolnshire, LN6 7TS, United Kingdom (email: 16662523@students.lincoln.ac.uk).

\section{Ethical Information}

No ethical approval was required for the following article as the article is a systematic literature review. The article is registered with PROSPERO, dated 27.07.2018, registration number CRD42018104461.

\section{Conflict of Interest}

The authors declare that they have no competing or potential conflicts of interest. 


\title{
The effectiveness of Theraplay for children under 12: A systematic literature review
}

\begin{abstract}
Background: Theraplay is a relationship-focused model of treatment based on attachment theory involving both adult and child. The study aims to review the quality of Theraplay research and Theraplay's effectiveness for children aged 12 years and under with a range of presenting difficulties, to inform future practice and identify areas for further research.
\end{abstract}

Methods: A systematic literature search was conducted using PsycINFO, CINAHL, MEDLINE, and Web of Science. Quantitative studies using Theraplay only as a treatment for children aged 12 years and under with any presenting difficulty were identified. Additional manual searching was conducted, including eligible studies' reference lists. Critical appraisal tools were used to provide a narrative synthesis of Theraplay's effectiveness and research quality.

Results: Only six eligible articles were identified, meaning there was a lack of rigorous evidence eligible to offer conclusions into Theraplay's effectiveness. The review highlighted the small evidence base, mixed quality research methodology and high levels of heterogeneity in how Theraplay is practiced and evaluated. Of the eligible studies, Theraplay was found promising in its effectiveness when used with internalising and externalising difficulties, dual diagnoses and developmental disabilities.

Conclusions: Theraplay is regularly practiced across the world; however, the evidence base of rigorous research to inform Theraplay's effectiveness and 
mechanisms of change is lacking. Firm conclusions could not be offered, although Theraplay was shown to be promising intervention for some presentations. Further research into Theraplay's effectiveness and key mechanisms of change are recommended to enhance the quality and depth of Theraplay literature.

\section{Key Practitioner Message:}

- Theraplay is an attachment-based intervention used within services across the world. Theraplay supports young people with various presentations and their family/care systems. Despite Theraplay's wide use, very little is known into its effectiveness and key mechanisms of change.

- The current evidence of Theraplay's effectiveness is based on a small number of studies, including high levels of heterogeneity of the articles, and poor quality methodology at times. Therefore, generalisability of the findings was difficult.

- Firm conclusions into Theraplay's effectiveness could not be established. Within the few studies included, Theraplay was shown to be a promising intervention for children presenting with internalising and externalising difficulties, dual diagnoses and developmental disabilities. Less promising evidence was seen for social and emotional difficulties with looked-afterchildren.

- More high quality and rigorous research is needed to fully establish the efficacy and effectiveness of Theraplay for children with various presenting difficulties, contributing to services use of evidence-based practice. 
Theraplay ${ }^{1}$ is an 'engaging, playful, relationship-focused treatment method that is interactive, physical and fun... based on attachment theory' (Booth \& Jernberg, 2009, p.xxi). Theraplay is used across countries and services for various presenting psychological difficulties and populations; including developmental disorders (e.g. Autistic Spectrum Disorders), attachment difficulties (including fostered or adopted children), trauma and regulation difficulties (both emotional and behavioural; Booth \& Jernberg, 2009; Munns, 2009; Wettig, Franke, \& Fjordbak, 2006).

Theraplay is informed by attachment theory and the work of Bowlby (1973), particularly the concept of inner working models. Children who experience pleasurable and attentive interactions with their caregivers develop a 'healthy' inner working model. Children view themselves, their parents (in turn others), and the world in a positive manner. Children with healthy inner working models develop a degree of safety; learning to explore their environment whilst knowing that the security of their parent will be there if needed. The Theraplay model hypothesises that children who have been neglected from these interactions are more likely to develop problem behaviours and relationship difficulties (Booth \& Jernberg, 2009). The rationale for Theraplay, therefore, is to offer the child and parent new positive interactions based on healthy and secure parent-infant attachments (Booth \& Jernberg, 2009). Sessions aim to enhance the child's internal working model and in turn, any problematic feelings and behaviours.

Theraplay differs in its application in comparison to typical Play Therapy. Play Therapy typically involves the child only, and play is used to explore the child's thoughts or feelings (e.g. in their choice of toy or play). Alternatively, Theraplay sessions involve both adult and child useg the relationship to create change (Booth \& Jernberg, 2009). Sessions focus on the 'here and now' interactions and not the child's past or present 
experiences (Theraplay Institute, 2017c). Theraplay is based on structured sessions underpinned by the four core concepts implemented through 'games'. Sessions provide the opportunity for the child to i) engage in an attuned connection (engagement), ii) a basis of safety (structure) and iii) the opportunities to experience mastery (challenge) and iv) feel worthy and cared for (nurture). Sessions follow a set structure (Booth \& Jernberg, 2009) and begin with games that implicitly communicate that the adults are excited to see them and reconnect between sessions (e.g. a 'check in'). The bulk of the session facilitates a combination of games based on the four concepts (e.g. playing 'slippery slip' with lotion [nurture] or 'balloon tennis' [challenge]). Sessions end with a transition back into everyday life, acknowledging the time they have all spent together. Theraplay sessions are designed to re-create early parentchild exchanges that would have typically occurred at an early age. Sessions go back to the original relationship that stems on the development on an inner working model (Munns, 2000). Sessions aim to support the key adult in providing face-to-face, positive, playful, and responsive interactions (Booth \& Jernberg, 2009) whilst enabling the development of a more positive inner working model for the child (Booth \& Winstead, 2016).

Attachment theorists propose that the attachment between primary caregiver and child acts as a dyadic regulation of emotion (Schore, 2000, 2001, 2005). The child's early experiences of emotion management are important in supporting the development in self-regulation skills, transitioning from parental co-regulation to child self-regulation. The development of self-regulation is an important aspect of the child's ability to develop good social skills (Gerhardt, 2004). Theraplay sessions promote the development of self-regulation using a combination of up and down regulating games 
(Munns, 2009), alongside the multiple opportunities for co-regulation by adults (firstly the therapist to parent/carer, then parent/carer to child; Booth \& Jernberg, 2009).

When implementing therapeutic models within services, it is important to consider and critically appraise its evidence base. Theraplay advertise their inclusion on the Substance Abuse and Mental Health Service Administration (SAMHSA, n.d.) National Registry for Evidence-based Programs and Practices. SAMHSA categorises Theraplay as 'effective' for internalising problems, and 'promising' for Autism Spectrum Disorder and Symptoms. Yet only two studies contribute to these results of effectiveness (Siu, 2009, 2014). One previous paper attempted to review the effectiveness of Theraplay for older children with attachment difficulties (Brayman, 2016). The review consisted of 11 peer-reviewed studies and concluded that Theraplay can be effective intervention to enhance change within childhood attachment (Brayman, 2016). However, several criticisms of the review weaken the validity of Brayman's (2016) claim. The review lacked systematic quality appraisal and involved a high degree of heterogeneity of the methodological design of studies, making it difficult to draw firm conclusions. The review also had levels of variability in how attachment was operationalised and measured. Most studies utilised methods of assessment that primarily assessed the nature and quality of parent-child interactions, rather than focusing solely on attachment security (Lindaman, Booth \& Chambers, 2000), and only one study utilising specific measures of attachment (Mahan, 1991).

Qualitative approaches have identified that practitioners, professionals and carers view Theraplay as being effective. Hong's (2014) study identified themes of Theraplay helping to build connections, decrease anxiety and depression, increase regulation and decrease aggression and 'temper tantrums.' The effectiveness of Theraplay with other presenting difficulties has also been reported, often via Theraplay newsletters 
(Theraplay Institute, 2017a). However, these were based on verbal accounts with no quantitative measures applied to monitor effectiveness objectively.

When establishing the utility of therapeutic models of intervention in clinical practise it is helpful to draw upon the current evidence-base to integrate information on efficacy. Salkovski's (1995) 'hourglass model' is a three-stage evaluation process during the clinical development of psychological intervention. The first stage involves the use of smaller samples and flexible methodological designs, followed by expanding to more stringent methodological strategies to assess efficacy and mechanisms of change, e.g. randomised control trials (RCTs). Finally, broadening any promising results to assess wider clinical utility.

Despite Theraplay's world-wide and broad use with various clinical presentations, a detailed systematic review is yet to be conducted to draw together the effectiveness of the model and the quality of current research. The current systematic literature review aims to establish the effectiveness of Theraplay for children with various presenting difficulties, using the 'hourglass model' of clinical development as a framework.

\section{Aims.}

The aims of the current systematic literature was to:

1) establish how the attachment-focused model of Theraplay is being applied to all presenting difficulties for children aged 12 years and under;

2) assess the effectiveness of Theraplay for children aged 12 years and under, for children presenting with various difficulties; 
3) provide a critical account of the summary of the results and the current literature, using a narrative review.

\section{Methods}

The systematic literature review was registered with PROSPERO, registration number CRD42018104461. The review was consistent with the Preferred Reporting Items for Systematic Reviews and Meta-Analyses (PRISMA) guidelines (Moher, Liberati, Tetzlaff \& Altman, 2009).

\section{Search Strategy.}

A search was conducted on: PsycINFO, CINAHL, MEDLINE and Web of Science. Each database was individually searched for studies published in English and between 1970 to July 2019. Reference lists of eligible full-text papers were also manually searched, alongside the recent Theraplay manual (Booth \& Jernberg, 2009) and Theraplay Institute website (Theraplay Institute, 2017a, 2017b). For any missing studies, contact was made with the Theraplay Institute alongside the use of interlibrary loans to enable completeness of the search (Petticrew \& Roberts, 2005).

There were a limited number of publications into Theraplay interventions. Following advice from an independent librarian, a specificity search was chosen due to the high volume of unsuitable papers included when combining the keyword of 'Theraplay' and the Medical Subject Heading (MeSH) of 'Play Therapy'. As outlined earlier, Theraplay and Play Therapy vary significantly in their approach and key mechanisms, which is further outlined by The Theraplay Institute (Theraplay Institute, 2017c). Therefore, it was felt that a study using the Theraplay treatment model should be explicit of its use of 'Theraplay' within the text. The search process was therefore broadened by 
searching the full text of studies and not restricting to abstracts and titles. All databases were searched using the free text Theraplay AND Child* (truncation for words including child, children, childhood). Table 1 presents the inclusion and exclusion criteria for the current systematic literature review, including a rationale for criteria.

Studies within the Theraplay manual (Booth \& Jernberg, 2009) were manually searched via titles only. Any eligible studies found via searching titles were then subject to a full text search.

[Insert Table 1 near here]

\section{Data Abstraction.}

Data extracted from eligible articles included; country, study design, population, sample size, range and average age of child, gender ratio, Theraplay treatment format, child-adult relationship in Theraplay, standardised measure used, who completed the measure, average number of sessions and frequency of sessions. Please refer to Table 2 for all abstracted data. Studies with mixed methodology only focused on the quantitative data.

\section{Quality Assessment.}

Meta-analyses and RCTs are deemed the most rigorous in design (Roth \& Fonagy, 2005). However, the methodological quality of any study is not to be assumed. Quality assessment enables the reader to establish whether the study provides confidence in its design and conduct (Boland, Cherry \& Dickson, 2014). No gold standard or recommended critical appraisal tool (CAT) of assessing quality and bias is available (Sanderson, Tatt \& Higgins, 2007). Nevertheless, the use of any CAT rather than none is recommended (Voss \& Rehfuess, 2012). The Joanna Briggs Institute (JBI) tools 
were chosen for the current review due to the range of study formats available, including case series (Moola et al., 2017), quasi-experimental designs and RCTs (Tufanaru, Munn, Aromataris, Campbell \& Hopp, 2017). Each tool was adapted to allow for additional quality appraisal checks relevant to the current study. Studies were assessed using the responses 'yes', 'no', or 'unclear'. All three authors independently coded each article to provide inter-rater reliability of the quality assessment.

\section{Results}

Of the original 534 studies identified (minus duplications), only six articles (seven studies) were eligible for review. A narrative review of study characteristics, study quality, and key findings shall be provided. A meta-analysis could not be completed due to the heterogeneity of participants, outcome measures, and timeframes (Boland et al., 2014).

\section{Selection Method.}

An overview of the search strategy is outlined in Figure 1. Initial searches (via electronic databases, the Theraplay Manual [Booth \& Jernberg, 2009], and Theraplay Institute website, $2017 \mathrm{a}, 2017 \mathrm{~b})$ identified 651 potentially relevant studies. A total of 110 studies were removed due to duplication, with 541 studies remaining. Each of these citations were screened by one reviewer to identify studies that did not meet inclusion criteria.

\section{[Insert Figure 1 near here]}

One hundred and fifty-three of the identified studies were removed as they were not in English, leaving 388 potential studies. A further 378 studies were excluded; $71.4 \%$ were published in a non-peer review format and $7.14 \%$ used an alternative model to 
Theraplay (e.g. Play Therapy, Filial Therapy). A full breakdown of each of the exclusion criteria met is in Supplement 1. Ten studies were eligible for full text review, however, four were excluded (see figure 1 for breakdown).

Attempts were made to source any missing studies via electronic searches, Librarians at the local university, Inter-Library Loans, and the author's (RM) contact with the Theraplay Institute. Despite exhaustive attempts, fifteen studies were removed as they were unable to be sourced.

Six articles were obtained and deemed eligible in the final review. One of these articles was written and published as one article (Wettig, Coleman \& Geider, 2011), yet reported two studies (a controlled longitudinal study and a multicentre study). These studies have been separated for the current review. For ease, eligible studies shall be referred to by numerical values (between 1-6b) for the remainder of the review. These are tabulated in Table 2.

Only one study from the previous Brayman (2016) review was found to be eligible in the current review (Bojanowsji \& Ammen, 2011). Eligibility criteria for the current review excluded several studies from Brayman's (2016) review, including; studies not being publishing in peer reviewed journals (Booth \& Winstead, 2015b; Mahan, 1991; Mason, 2007; Myrow, 2016), a qualitative project (Hong, 2014), studies integrating their intervention (Weir, 2007; Weir et al., 2013), recruiting a participant older than 12 (Robison, Lindaman, Clemmons, Doyle-Buckwater \& Ryan, 2009), and not implementing any quantitative measures (Booth \& Lindaman, 2000; Myrow-Bundy \& Booth, 2009). Four of the studies included in the current review were published in the wider literature but not included within Brayman's (2016) review (Francis, Bennion \& 
Humrich, 2017; Hiles Howard, Lindaman, Copeland \& Cross, 2018; Siu, 2009, 2014; Wettig et al., 2011).

[Insert Table 2 near here]

\section{General Characteristics}

Studies were conducted in various countries across the world. Participant sample sizes ranged from $8-167$, with $63 \%$ of participants male with a mean age range (where reported) of 4.1 to 10.34 years. Most participants were male $($ male $=195$, female $=114)$.

The most common study design was case series designs using pre-post measures (1, 2, 3, 6b). Two studies utilised RCT $(4,5)$. Table two presents the high levels of variability between studies; including, the setting Theraplay was implemented (e.g. home or school), the key adult involved (e.g. parent or teacher), the frequency of sessions (e.g. daily or weekly) and whether sessions were 1:1 or group. Where reported, the mean number of sessions ranged between 8-19 sessions, with a reported range of 4-66 sessions. Clinical heterogeneity of how Theraplay interventions are delivered is evident, and subsequently impacts the ability to draw accurate conclusions (Gagnier, Moher, Book, Beyene \& Bombardier, 2012). Results from the current review will be based on using narrative synthesis and relating this to the population, intervention, comparison, and outcome (PICO), as recommended when clinical heterogeneity is present (Gagnier et al., 2012).

\section{Quality Appraisal Results}

All seven studies (six articles) were quality appraised by all three authors. Inter-rater reliability, using Fleiss' kappa, found a 'substantial agreement' $(k a p p a=0.63)$ between 
authors as informed by Landis and Koch's (1977) criteria. Results from each of the CATs are tabulated in Table 3, 4 and 5, with the majority quality appraisal presented.

One study acknowledged no affiliation with the Theraplay Institute in their article (2), with three of the studies seen to have some association with the Theraplay Institute $(3,6 a, 6 b)$. None of the studies reported who had funded the research. Overall, this variance in reporting places the studies at risk to researcher and funding bias.

Mixed results were found in how studies reported the procedure and typical session of the Theraplay intervention, with Group Theraplay studies applying this better $(2,4$, 5). An example session plan was only provided by one study (5). Theraplay recommends the transition of key adults into the Theraplay sessions (Booth \& Jernberg, 2009). However, studies were inconsistent on reporting how the transition was managed. Some studies reported that this transition occurred $(4,6 a, 6 b)$ with only one study being clear on the duration of the adult's participation in sessions and that the child did not participate in all sessions offered (3). This fluctuation and lack of clarity comprises the studies validity and reliability.

Only one study (1) measured change between the four core concepts of Theraplay (structure, challenge, nurture and engagement). Studies explanations of how the child's presenting problem was related to the attachment-theory underpinnings of Theraplay were not always clear and fully established. Studies also varied in their assessment measures, with self-report measures (completed by key adults involved) frequently used $(1,2,4)$, which enhances the likelihood of reporting bias. 
Most studies used appropriate statistical analysis. Three studies did not report effect sizes $(2,6 a, 6 b)$. Missing effect sizes were calculated by the researcher for the purpose of the systematic review. The small sample sizes in some studies and one study's multiple use of the same data (2) increased the risk of type 1 error.

[Insert Tables 3, 4, 5 near here]

\section{'Hourglass Model'}

Despite the inclusion criteria being narrow in areas to enhance the quality of studies included (i.e. peer reviewed journal articles), the criteria were broad in others (e.g. children aged 0-12 years with any presenting difficulty). Despite this, only seven studies were included within the review. The small number of studies raises questions in relation to the 'hourglass model' of psychological intervention and what evidence current services are basing their decisions on when implementing Theraplay, given the small number of studies included.

Randomised Control Trials (RCT). RCTs are deemed to be one of the most rigorous research designs (Roth et al., 2005). Two RCTs were included in the review $(4,5)$. Both studies lacked information about the process of randomisation, how the control group post-measures were collected $(4,5)$, and differences between the control and treatment groups (5). The inclusion of only two RCTs also raises doubt whether the true effectiveness of Theraplay has been determined to broaden its use within the 'hourglass model' (Salkovski, 1995).

Case Series / Quasi Experimental Design. Studies implementing a case series design lacked in the identification and reporting the child's presenting difficulties, alongside missing inclusion/exclusion criteria. All studies used a pre-post 
study design (1, 2, 3, 6a) alongside additional follow-up (6a). Whilst the multicentre case series study reported the use of a control group (6b), the data was found to be from another study dataset (6a), which raised concerns of how comparable the control group was in relation to the treatment group (e.g. recruited at a different time and country). A limitation of case series designs means that any effects found cannot be truly explained by the intervention itself. Results may have been due to other factors such as maturation of participants, information given about Theraplay, or effects of completing the measures themselves (Marsden \& Torgerson, 2012). Any changes observed may have also naturally occurred without intervention.

\section{Presenting Difficulties}

Significant results are reported at the recommended $p<.05$ (Dancey \& Reidy, 2017), with Cohen's $d$ effect sizes at 0.2 (small), 0.5 (medium), 0.8 (large), (Cohen, 1988). The small number of studies, however, means that firm conclusions about Theraplay's effectiveness for the following presentations cannot be made.

Internalising (emotional) and externalising (behavioural) difficulties. Two studies found a statistically significant decline, with meaningful effect, in children's internalising difficulties following intervention $(1,4)$. Significant changes in children's internalising difficulties were found for both individual Theraplay (1) and group Theraplay (4), with group Theraplay being superior when compared with a waitlist control group. A significant change in total problems and externalising difficulties were also found following intervention (1), with moderately large to large effect.

Dual diagnosis. Two studies assessed Theraplay's effectiveness for children with a dual diagnosis of a language disorder and clinical shyness/social anxiety (6a, 6b). Both studies found meaningful change following Theraplay intervention. A 
statistically significant improvement with meaningful effect was found in attention, cooperation, and levels of conformity alongside a significant decline with meaningful effect in children's levels of shyness, social withdrawal, and mistrust (6a). Receptive language skills also significantly improved following intervention, with these changes maintained at two-year follow up. Interestingly, a statistically significant change between post-intervention and two-year follow up was also found with children's expressive language skills.

When expanded to a multicentre design (6b), all areas of clinical shyness were found to statistically improve, including symptoms of attention, cooperation, levels of conformity, social withdrawal, mistrust, and low self-confidence. Children's expressive and receptive language skills also significantly improved. When these results were compared with the control group results from the subsequent study (6a), although results are to be interpreted with caution, significant improvements with medium to large effect were found in children's self-confidence, expressive and receptive language skills, alongside a decline in social withdrawal.

Social and emotional needs of looked after children (LAC). No significant changes were found when using Theraplay for LAC with social and emotional needs (2) either in 1:1 or group delivery. Results may have been impacted by the chosen measures difficulties in being sensitive to change (Wolpert, Cheng, \& Deighton, 2015).

Developmental disabilities. When Theraplay was implemented with children diagnosed with Autistic Spectrum Disorders (ASD), there was a statistically significant improvement in positivity, eye contact, and acceptance of guidance (3). Improvements were maintained at 3-month follow up. No changes were found in children's observed affect, body positioning towards parent, responsivity to cues from parent, and 
attentiveness to task. When 1:1 Theraplay intervention was broken down into four time points, children's levels of positivity, body positioning towards parent, and acceptance of guidance was found to statistically improve as the sessions progressed. No effect sizes, exact $p$ values, or standard deviations were reported to determine the effect of intervention.

Group Theraplay was found to be more effective than school lessons as usual (control group) for children with mild or moderate Intellectual Disabilities (5) with a small but significant effect was shown, including significant changes in children's social awareness, social cognition, social communication, and social motivation.

Adult-child relationship. Few studies acknowledged or monitored changes within the adult-child relationships. Significant improvements with meaningful effect were found between parent and child within the Theraplay domains of challenge and nurture following 1:1 Theraplay (1). No significant changes within the parents use and child's response to structure and engagement were found after the use of Theraplay.

No significant changes were found within the overall relationship when assessed with families of children with ASD (3). However, a significant improvement in parent's facial expression and affect, response to behavioural cues, eye contact towards child, and offering of guidance was found following Theraplay. These behaviours, alongside parent's encouragement, were found to statistically improve as the sessions progressed over time. This pattern of progression was not statistically significant for parental eye contact. Effect sizes could not be established therefore the true magnitude of this effect cannot be concluded.

Treatment. Where reported or calculated, 1:1 Theraplay sessions demonstrated more meaningful effect (ranging from moderate to large). Group 
Theraplay was also found to show meaningful change, however, there was a broader range of effect (small to large). Firm conclusions cannot be made due to variance between studies, missing information, and more studies using a 1:1 format.

\section{Discussion}

The primary aim of this review was to assess the effectiveness of Theraplay for children aged 12 years with various presenting difficulties. Alternatively, the review highlighted the lack of rigorous research into Theraplay's evidence base. Whilst the current review is not considered an 'empty' review (Lang, Edwards, \& Fleiszer, 2007), the lack of studies means that the results could not be synthesised to draw a conclusion into Theraplay's evidence base for children under 12. Nonetheless, Theraplay is a well-practiced intervention across the world, and the review is considered important to raise awareness into Theraplay's scant evidence base (Schlosser \& Sigafoos, 2009).

Of the few studies included, only one study from a previous review (Brayman, 2016) was eligible for the current review (Bojanowski et al., 2011). Of the small sample, mixed results were found regarding the effectiveness of Theraplay, compounded by the mixed quality and potential biases of studies.

Theraplay was seen to be effective for children with internalising difficulties and a dual diagnosis of a language disorder and clinical shyness/social anxiety. Most of the changes were found when expanding the design to multiple clinical settings and after a 2-year follow up, suggesting the generalisability and longevity of the effectiveness of Theraplay for this population group. 
Mixed results were found for children with developmental disabilities. Theraplay was found to be more effective at enhancing social difficulties than usual school classes for children with ID, whereas some (but not all) changes within the parent-child relationship were found following Theraplay for children with ASD. The least meaningful change was using Theraplay for children with intellectual disabilities and improving social responsiveness. Theraplay was not found to be effective at reducing social and emotional difficulties for LAC, with no significant changes observed following intervention. Interestingly, this was the only study that explicitly reported that they had no affiliation with the Theraplay Institute. Whilst tentative conclusions can be drawn into the effectiveness of Theraplay in comparison to control groups, most of these results can only provide inferences that Theraplay is better than nothing due to their pre-post design.

It is important to consider the methodological quality of the studies included in the review. Demographic data was presented well across most studies. However, there were many inconsistencies in how Theraplay intervention was delivered and a high level of heterogeneity between studies. Most studies utilised a case series design, which were poor at providing clear details regarding their inclusion/exclusion criteria and participant selection process. Furthermore, the two RCT studies lacked information into their randomisation process and how control group data was collected.

The foundations of attachment theory within the Theraplay model are widely promoted. Studies included in the review varied in their explanations of how the presenting problem related to the theory. Theraplay acknowledges the central role of parents supporting the child in learning self-regulation skills, which could be supported within some of the changes found. However, Theraplay promotes their goal to 'change the child's inner working model through interactions that are responsive, attuned, 
empathic and reflective' (Booth \& Jernberg, 2009, p57-58). Firstly, measuring an internalised concept of inner working models leads to challenges itself. Secondly, none of the studies included monitored any changes related to children's attachment presentations. Therefore, it is difficult to establish whether the changes observed were related to changes in attachment and inner working models, as the Theraplay model would suggest.

Theraplay's inclusion of key adults (e.g. parent, teacher) highlights the role of modelling and social learning theory within the approach (Bandura, 1978). During the initial sessions, the Theraplay therapists model the Theraplay games to parents/carers whilst they observe. The lead adult is then transitioned to the from the therapist to the parent/carer to take a lead of the games/sessions. It could therefore be suggested that modelling provides a key mechanism and underlying process of change for children within the Theraplay model. Previous qualitative research identified the theme of experiential learning and modelling from parental focus groups (Hong, 2014). However, only one study measured any parental change during and following intervention. Significant changes were found, but no account was provided into how these changes may or may not have contributed to any changes with the child.

Despite the Theraplay model's establishment in 1970, and the broadness of this review question, it was surprising to find only six eligible articles and the high level of heterogeneity and quality within these articles. A final aim of the review was to establish the evidence of Theraplay in line with the hourglass model (Salkovski, 1995) and its current implementation within services. Theraplay literature remains in the early stages of establishing a rigorous evidence base. Most of the literature utilises clinical perspective and smaller scale exploratory studies, and only two RCTs found using the current reviews criteria. Theraplay's use, however, has broadened out within clinical 
practise and presenting difficulties, despite previous acknowledgements for the need of more rigorous research and publications in peer-reviewed journals (Munns, 2000; Wardrop \& Meyer, 2009). Despite the lack of rigorous, quantitative evidence, many therapists and services who utilise Theraplay validate their experience of its effectiveness (Francis Bennion \& Humrich, 2017; Hong, 2014). There are many arguments for practice-based evidence of integrating expertise and service-led parameters (Barkham, Stiles, Lambert \& Mellor-Clark, 2010).

\section{Limitations}

Specificity and sensitivity searches were conducted in the current review to establish the most effective search terms. Despite this, the high number of initial studies found during searches, in comparison to those that met inclusion criteria, highlights potential limitations with the search process. The search process is likely to have excluded studies that focused on the adult role and associated factors within the Theraplay sessions, and may explain some of the missing information included within the study.

The absence of eligible studies may reflect a lack of research within the area. However, the inclusion of published studies only, and the exclusion of studies that reported the use of Theraplay with other approaches, also places the review at risk of publication bias. The quality appraisal process and heterogeneity between studies also made it difficult to draw firm conclusions in relation to the primary aim of the review.

Finally, it is important to acknowledge that none of the authors completing the review has no affiliation with the Theraplay Institute. However, two researchers (RM and SW) have completed the Level One Theraplay training established by the Theraplay Institute (2017d). This may have led to some reporting bias within the review process. 


\section{Future Research}

Firstly, future research into Theraplay needs to be of higher quality, using more robust and rigorous methodological design. Research monitoring any changes to children's attachment patterns and the underlying premise of the Theraplay model would be advantageous. Monitoring process mechanisms within Theraplay sessions (i.e. games related to the four core concepts) would provide the opportunity to evaluate change in the client's presenting difficulties and investigate what the key ingredients to change are. Further research into the role of the key adult within sessions (either parent/carer or teacher), including the modelling process between therapist and adult, would also be of benefit. Finally, more published research into the effectiveness and efficacy of Theraplay for various presentations is recommended. More published research would provide clarity into whether Theraplay is an effective model for children's mental health difficulties and contribute to its implementation within services worldwide.

With these recommendations in mind, it would also be helpful to consider why there is a lack of high quality and rigorous research when using the Theraplay model, which may help to address any potential barriers.

\section{Conclusion}

Theraplay is a well-used approach for many children and families with various presenting difficulties. Despite Theraplay's implementation in services, the current review highlights the lack of rigorous research conducted into its effectiveness and mechanisms of change for children aged 12 years and under. Whilst some promising findings are suggested, a maximum of two studies for each presenting problem were found eligible within the current systematic literature review with quality appraisal tools highlighting limitations of the eligible studies. The current systematic literature review 
suggests that Theraplay's practice is ahead of research and a rigorous evidence base, with further research into its effectiveness warranted.

\section{Acknowledgments:}

This systematic literature review was funded by the University of Lincoln and was completed as part of the Trent Doctorate in Clinical Psychology for author ${ }^{*} R E M O V E D^{*}$. The protocol and review was registered on the PROSPERO database (registration number CRD42018104461). The authors declare that they have no competing or potential conflicts of interest. The authors would like to thank librarians at the University of Lincoln and the Research Director at the Theraplay Institute for their contribution in supporting the access of articles within the literature searches.

\section{Notes:}

${ }^{1}$ Theraplay is a registered service mark of The Theraplay® Institute, Evanston, IL, USA. 


\section{References}

Achenbach, T. M., \& Rescorla, L. (2001). Manual for the ASEBA school-age forms and profiles. Burlington: University of Vermont, Research Centre for Children, Youth \& Families

Bandura, A. (1978). Social learning theory of aggression. Journal of Communication, 28(3), 12-29.

Barkham, M., Stiles, W. B., Lambert, M. J., \& Mellor-Clark, J. (2010). Building a rigorous and relevant knowledge base for the psychological therapies. In M. Barkham, G. E. Hardy, \& J. Mellor-Clark (Eds.), Developing and Delivering Practice-Based Evidence: A Guide for the Psychological Therapies (pp.21-61). West Sussex: John Wiley \& Sons Ltd.

Bojanowski, J. J., \& Ammen, S. (2011). Discriminating between pre-versus posttheraplay treatment marschak interaction methods using the marschak interaction method rating system. International Journal of Play Therapy, 20(1), 1-11. doi:10.1037/a0022668

Booth, P. B., \& Jernberg, A. M. (2009). Theraplay: Helping parents and children build better relationships through attachment-based play. San Francisco, CA: John Wiley \& Sons.

Boland, A., Cherry, M., \& Dickson, R. (Ed.). (2014). Doing a Systematic Review: A Student's Guide. London: SAGE Publications. 
Booth, P. B., \& Lindaman, S. (2000). Theraplay for enhancing attachment in adopted children. In H. G. Kaduson \& C. E. Schaefer (Eds.), Short Term Play Therapy for Children (pp. 194-227). New York: Guilford Press.

Booth, P. B., \& Winstead, M. L. -R. (2015). Theraplay ${ }^{\circledR}:$ Repairing relationships, helping families heal. In D. A. Crenshaw \& A. L. Stewart (Eds.), Play therapy: A comprehensive guide to theory and practice (pp. 141-155). New York: Guilford Press.

Booth, P. B., \& Winstead, M. L. -R. (2016). Theraplay: Creating secure and joyful attachment relationships. In K. J. O'Connor, C. E. Schaefer \& L. D. Braverman (Eds.), Handbook of play therapy (pp. 165-194). John Wiley \& Sons: New Jersey.

Bowlby, J. (1973). Attachment and loss: Vol. 2. Separation Anxiety and Anger. London: Hogarth Press.

Brayman, R. (2016). The effectiveness of Theraplay as treatment for older children with attachment difficulties (Unpublished masters dissertation). St Catherine University, University of St. Thomas, Minnesota.

Cohen J. (1988). Statistical Power Analysis for the Behavioral Sciences. New York, NY: Routledge Academic

Constantino, J. N., Davis, S. A., Todd, R. D., Schindler, M. K., Gross, M. M., Brophy, S. L., Metzger, L. M., Christiana, S. S., Splinter, R. \& Reich, W. (2003). Validation of a brief quantitative measure of autistic traits: Comparison of the social responsiveness scale with the autism diagnostic interview-revised. Journal of Autism and Developmental Disorders, 33(4), 427-433. 
Dancey, C. \& Reidy, J. (2017). Statistics without maths for psychology. Harlow: Pearson Education Limited.

Döpfner, M., Berner, W., Flechtner, H., Lehmkuhl, G., \& Steinhausen, H. C. (1999). Psychopathologisches Befund-System für Kinder und Jugendliche:(CASCAP-D). [Clinical Assessment Scale for Child and Adolescent Psychopathology (CASCAP-D)]. Germany: Hogrefe Verlag für Psychologie.

Francis, Y. J., Bennion, K., \& Humrich, S. (2017). Evaluating the outcomes of a school based theraplay ${ }^{\circledR}$ project for looked after children. Educational Psychology in Practice, 33(3), 308-322. doi:10.1080/02667363.2017.1324405

Gagnier, J. J., Moher, D., Boon, H., Beyene, J., \& Bombardier, C. (2012). Investigating clinical heterogeneity in systematic reviews: A methodologic review of guidance in the literature. BMC Medical Research Methodology, 12(1), 111. doi:10.1186/1471-2288-12-111

Gerhardt, S. (2004). Why love matters: How love shapes a baby's brain. Hove: Brunner Routledge.

Goodman, R. (1997). The strengths and difficulties questionnaire: A research note. Journal of Child Psychology and Psychiatry, 38(5), 581-586. https://doi.org/10.1111/j.1469-7610.1997.tb01545.x

Hiles Howard, A. R., Lindaman, S., Copeland, R., \& Cross, D. R. (2018). Theraplay impact on parents and children with autism spectrum disorder: Improvements in affect, joint attention, and social cooperation. International Journal of Play Therapy, 27(1), 56-68. http://dx.doi.org/10.1037/pla0000056 
Hong, R. (2014). Practitioners' evaluations of Theraplay as an effective tool in serving foster and adopted children and their families (Unpublished doctoral dissertation). Loyola University Chicago, Chicago.

Landis, R. J., \& Koch, G. G. (1977). An application of hierarchical kappa-type statistics in the assessment of majority agreement among multiple observers. Biometrics, 33, 363-374.

Lang, A., Edwards, N., \& Fleiszer, A. (2007). Empty systematic reviews: Hidden perils and lessons learned. Journal of Clinical Epidemiology, 60, 595-597. doi:10.1016/j.jclinepi .2007.01.005

Lindaman, S. L., Booth, P. B. and Chambers, C. L. (2000). Assessing parent-child interactions with the Marschak Interaction Method (MIM). In K. Gitlin-Weiner, C. Schafer, \& A. Sandgrund (Eds.), Play Diagnosis and Assessment, Volume II (pp. 371-400). New York: Wiley.

Mahan, M.G. (1999). Theraplay as an intervention with previously institutionalized twins having attachment difficulties (Unpublished doctoral dissertation). Chicago, IL: The Chicago School of Professional Psychology.

Marsden, E., \& Torgerson, C. J. (2012). Single group, pre-and post-test research designs: Some methodological concerns. Oxford Review of Education, 38(5), 583-616. http://dx.doi.org/10.1080/03054985.2012.731208

Mason, C. M. (2007). Parent and therapist perceptions of therapy with a late -placed foster or adopted child (Unpublished doctoral dissertation). Loyola University Chicago, Chicago. 
McKay, J. M., Pickens, J., \& Stewart, A. L. (1996). Inventoried and observed stress in parent-child interactions. Current Psychology, 15(3), 223-234. https://doi.org/10.1007/BF02686879

Moher D, Liberati A, Tetzlaff J, Altman DG, The PRISMA Group (2009). Preferred Reporting Items for Systematic Reviews and Meta-Analyses: The PRISMA Statement. PLoS Med 6(7): e1000097. doi:10.1371/journal.pmed1000097

Moola S, Munn Z, Tufanaru C, Aromataris E, Sears K, Sfetcu R, Currie M, Qureshi R, Mattis P, Lisy K, Mu P-F. Chapter 7: Systematic reviews of etiology and risk. In: Aromataris E, Munn Z (Editors). Joanna Briggs Institute Reviewer's Manual. The $\begin{array}{cccc}\text { Joanna } & \text { Briggs } & \text { Institute, } & \text { Retrieved }\end{array}$ from https://reviewersmanual.joannabriggs.org/

Munns, E. (Ed.). (2000). Theraplay: Innovations in attachment-enhancing play therapy. New York, NY: Jason Aronson.

Munns, E. (Ed.). (2009). Applications of family and group Theraplay. New York, NY: Jason Aronson.

Myrow, D. L. (2016). Enjoying theraplay with school-age children. In A.A. Drewes, \& C.E. Schaefer (Eds.), Play therapy in middle childhood (pp. 115-133). Washington: American Psychological Association.

Myrow-Bundy, S., \& Booth, P. B. (2009). Theraplay: Supporting attachment relationships. In K. J. O'Connor \& L. D. Braverman (Eds.). Play therapy theory and practice: Comparing theories and techniques (pp. 315-366). Hoboken, US: John Wiley \& Sons Inc. 
O’Connor, K., Ammen, S., Backman, T. L., \& Hitchcock, D. (2001). The Marschak Interaction Method Rating System (Unpublished instrument). Alliant International University, Fresno, CA.

Petticrew, M., \& Roberts, H. (2005). Systematic reviews in the social sciences: A practical guide. USA: Blackwell Publishing.

Robison, M., Lindaman, S., Clemmons, M., Doyle K., \& Ryan, M. (2009). "I Deserve a Family": The evolution of an adolescent's behavior and beliefs about himself and others when treated with theraplay in residential care. Child \& Adolescent Social Work Journal, 26(4), 291-306.

Roth, A., \& Fonagy, P. (2005). What works for whom? A critical review of psychotherapy research (2 $2^{\text {nd }}$ ed.). New York: The Guilford Press.

Salkovskis, P. M. (1995). Demonstrating specific effects in cognitive and behavioural therapy. Research Foundations for Psychotherapy Practice, 191-228.

Sanderson, S., Tatt, I. D., \& Higgins, J. (2007). Tools for assessing quality and susceptibility to bias in observational studies in epidemiology: A systematic review and annotated bibliography. International Journal of Epidemiology, 36(3), 666676. https://doi.org/10.1093/ije/dym018

Schlosser, R. \& Sigafoos, J. (2009). 'Empty' reviews and evidence-based practice. Evidence-based Communication Assessment and Intervention, 39(1), 1-3. DOI: $10.1080 / 17489530902801067$

Schore, A., N. (2000). Attachment and the regulation of the right brain. Attachment and Human Development, 2 (1), 23-47. 
Schore, A., N. (2001). Effects of a secure attachment relationship on right brain development, affect regulation and infant mental health. Infant Mental Health Journal, 22, 7-66.

Schore, A., N. (2005). Attachment, affect regulation, and the developing right brain: linking developmental neuroscience to pediatrics. Pediatrics in Review, 26, 204217.

Siu, A. F. (2009). Theraplay in the chinese world: An intervention program for hong kong children with internalizing problems. International Journal of Play Therapy, 18(1), 1-12. doi:10.1037/a0013979

Siu, A. F. (2014). Effectiveness of group theraplay $\AA^{\circledR}$ on enhancing social skills among children with developmental disabilities. International Journal of Play Therapy, 23(4), 187-203. http://dx.doi.org/10.1037/a0038158

Substance Abuse and Mental Health Service Administration (n.d.). National registry for evidence-based programs and practices. Theraplay. Retrieved from http://nrepp.samhsa.gov/ProgramProfile.aspx?id=156\#hide3 on $14^{\text {th }}$ July 2018.

Theraplay Institute (2017a). Articles about Theraplay. Retrieved from https://www.theraplay.org/index.php/articles-about-theraplay on 14 th July 2018.

Theraplay Institute (2017b). Theraplay treatment outcome research. Retrieved from https://www.theraplay.org/index.php/theraplay-research on 14 th July 2018.

Theraplay Institute (2017c). How Theraplay differs from other child therapies. Retrieved from https://www.theraplay.org/index.php/how-theraplay-differs on 14 ${ }^{\text {th }}$ July 2018. 
Theraplay Institute (2017d). Theraplay, professional training. Retrieved from https://www.theraplay.org/index.php/training on $3^{\text {rd }}$ August 2018.

Tufanaru C, Munn Z, Aromataris E, Campbell J, Hopp L. Chapter 3: Systematic reviews of effectiveness. In: Aromataris E, Munn Z (Editors). Joanna Briggs Institute Reviewer's Manual. The Joanna Briggs Institute, 2017. Available from https://reviewersmanual.joannabriggs.org/

Voss, P. H., \& Rehfuess, E. A. (2012). Quality appraisal in systematic reviews of public health interventions: An empirical study on the impact of choice of tool on metaanalysis. Journal of Epidemiology and Community Health, 67(1), 98-104. doi:10.1136/jech-2011-200940.

Wardrop J, L., \& Meyer, L, A. (2009). Research on Theraplay Effectiveness. In E, Munns (Eds.), Applications of family and group Theraplay (pp. 17-26). USA: Jason Aronson.

Weir, K. N. (2007). Using integrative play therapy with adoptive families to treat reactive attachment disorder: A case example. Journal of Family Psychotherapy, 18(4), 116. doi:10.1300/J085v18n04_01

Weir, K. N., Lee, S., Canosa, P., Rodrigues, N., McWilliams, M., \& Parker, L. (2013). Whole family theraplay: Integrating family systems theory and theraplay to treat adoptive families. Adoption Quarterly, 16(3-4), 175-200.

Wettig, H. H., Coleman, A., \& Geider, F. J. (2011). Evaluating the effectiveness of theraplay in treating shy, socially withdrawn children. International Journal of Play Therapy, 20(1), 26-37. doi:10.1037/a0022666 
Wettig, H. H. G., Franke, U., \& Fjordbak, B. S. (2006). Evaluating the Effectiveness of Theraplay. In C. E. Schaefer \& H. G. Kaduson (Eds.), Contemporary play therapy: Theory, research, and practice (pp. 103-135). New York, NY, US: Guilford Press.

Wolpert, M., Cheng, H., \& Deighton, J. (2015). Measurement Issues: Review of four patient reported outcome measures: SDQ, RCADS, C/ORS and GBO-their strengths and limitations for clinical use and service evaluation. Child and Adolescent Mental Health, 20(1), 63-70. doi:10.1111/camh.12065 


\section{Figures and Tables}

Figure 1

PRISMA diagram showing study selection process

Studies retrieved through electronic databases:

PsycINFO, CINAHL, MEDLINE, Web of Science. $(n=216)$
Studies retrieved through Manual Search:

Theraplay Manual (Booth \& Jernberg, 2009),

Theraplay Institute (2017a, 2017b). ( $n=435)$

\section{Studies excluded:}

Not English, not in a peer reviewed article, published before 1970, Qualitative project, no outcome measure/experimental design, Adult/Adolescent Population, Combination of Therapies, Not Theraplay, Unable to Access Text

$$
(n=531)
$$

Potentially eligible studies accessed in full copy $(n=10)$

\section{Articles excluded:}

Unable to access full copy $(n=1)$, Measure focused on parent and combined approach $(n=1)$, No ages given $(n=1)$, Mixed intervention and no standardised measure $(n=1)$ :

Total excluded: $(n=4)$

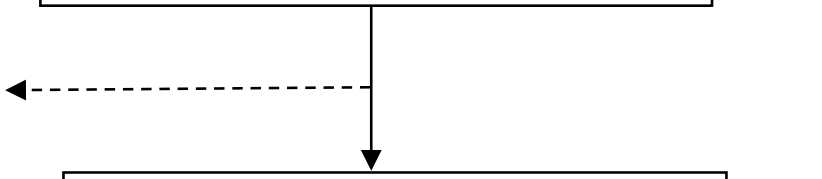

\section{Full text articles considered for} inclusion $(n=6)$

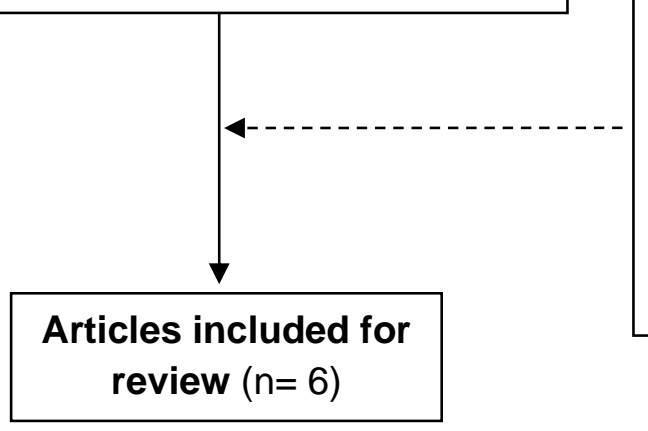

\section{Manual search:}

Articles identified from reference lists of relevant studies, and retrieved for examination $(\mathrm{n}=0)$ 
Table 1

Inclusion and exclusion criteria for study selection process.

\section{Inclusion Criteria}

Average age of child in study to be 12 years old

or under, either male or female

Study to contain the word 'Theraplay' as specific

model of therapy offered

Use of outcome using a psychometric measure,

quantitative study

To be written in English

Due to constraints of the study and being unable to translate.

\section{Rationale} and therefore use with infants and toddlers recognised and accredited by the Theraplay Institute. problem, Theraplay) and their relationship.
To build on the review by Brayman (2016), and Theraplay's non-verbal modality

To establish the specific model of Theraplay is being used within the study, as

o establish empirical investigation of the phenomena in question (i.e. presenting

To capture a broader range of quantitative research, which can then be quality appraised

experimental designs)

Minimum quality threshold

In a peer-reviewed journal

The year the Theraplay Institute was established. 


\section{Exclusion Criteria}

Dissertations/Theses

Studies published in other formats: Books

(including full books, chapters or reviews),

Conference papers/abstracts, Films, Magazines,

Newspapers, Newsletters.

Other play model used e.g. Filial Therapy, Play

Therapy

Theraplay combined with another approach (e.g.

Dyadic Developmental Psychotherapy)

\section{Rationale}

Not peer reviewed, with less scientific rigour.

Not peer reviewed, with less scientific rigour.

\section{These models not being recognised or attributed to the Theraplay model, as} accredited by the Theraplay Institute.

Difficulties in distinguishing the mechanisms of change, and whether this is specifically due to Theraplay or the other model of combined choice. 

rationale. 
Table 2

Study characteristics for eligible studies.

\begin{tabular}{|c|c|c|c|c|}
\hline $\begin{array}{c}\text { Author(s), } \\
\text { Year, }\end{array}$ & Methodology & Sample Characteristics & $\begin{array}{c}\text { Intervention } \\
\text { Characteristics }\end{array}$ & Summary of Results \\
\hline \multicolumn{5}{|l|}{ Country } \\
\hline 1) & Quantitative. & Setting: Private & Treatment Type: $1: 1$ & - CBCL: Decline in externalising problems* \\
\hline Bojanowski, & Case series. & outpatient clinic & Assessment: MIMRS & $(d=0.72), \quad$ total problems ${ }^{* *} \quad(d=1.14)$ and \\
\hline J. J., \& & & Presenting difficulty: & (O'Connor, Ammen, & internalising problems ${ }^{* *}(d=1.10)$ post Theraplay. \\
\hline Ammen, $\mathrm{S}$. & Pre/post & Internalising/Externalising & Backman \& Hitchcock, & - MIMRS: Improvement in total scores ${ }^{*}(d=1.07)$ \\
\hline (2011). & data, no & difficulties. & 2001); CBCL (Achenbach & post Theraplay, alongside parents use and childs \\
\hline \multirow[t]{6}{*}{ Canada } & follow up. & Sample Size: 11 parent- & \& Rescorla, 2001). & response to nurture ${ }^{* *}(d=1.50)$ and challenge ${ }^{*}$ \\
\hline & & child dyads (8 children in & Session No: Minimum 8 & $(d=0.76)$. No significant change found for \\
\hline & Inferential & total). & (range or mean not & structure and engagement scale, alongside \\
\hline & statistics. & Age: Mean $=6.55$ years & reported). & separation task $(p>.05)$ \\
\hline & & $(\mathrm{SD}=1.63)$, Range $=5-9$ & Frequency of sessions: & \\
\hline & & years. & Not reported. & \\
\hline
\end{tabular}




\section{Gender: Female $(n=5)$,}

male $(n=3)$.

\begin{tabular}{|c|c|c|c|c|}
\hline 2) & Mixed & Setting: School/Home & Treatment Type: $1: 1$ and & - Combination of 1:1 and Group: No \\
\hline Francis, Y. & Methods. & Presenting difficulty: & group (child and significant & statistically significant change on all scales of \\
\hline J., Bennion, & Case series. & LAC, social and & adult in school, e.g. & the SDQ ( $p>.05)$, including emotional, \\
\hline K., \& & & emotional difficulties & teacher, behaviour & hyperactivity, conduct, peer problems, prosocial \\
\hline Humrich, S. & Pre/post & Sample Size: $40(20$ & mentor) & and total. \\
\hline (2017). & data, no & LAC, 20 non-LAC) & Assessment: SDQ & - 1:1 intervention: No statistically significant \\
\hline \multirow[t]{6}{*}{ UK } & follow up. & Age: Range 5-11 years & (Goodman, 1997) & change on all scales of the SDQ $(p>.05)$, \\
\hline & & (no mean data). & Session No: Group: 4-16 & including emotional, hyperactivity, conduct, peer \\
\hline & Inferential & Gender: Female $(n=11)$, & sessions, 1:1 12-18 & problems, prosocial and total. \\
\hline & statistics. & male $(n=9)$ & sessions. & - Group: No statistically significant change on all \\
\hline & & & Frequency of sessions: & scales of the SDQ ( $p>.05)$, including emotional, \\
\hline & & & Weekly, 30 minutes each. & $\begin{array}{l}\text { hyperactivity, conduct, peer problems, prosocial } \\
\text { and total. }\end{array}$ \\
\hline
\end{tabular}


- Differences between group and 1:1 scores:

Significant differences between pre and post total scores, hyperactivity and conduct problems, and prosocial behaviours. A significant difference between post only peer problems. No significant differences between emotional pre and post scores, alongside peer problems prescores only ( $p>.05)$. No $p$ values given.

\begin{tabular}{lllll}
\hline 3) & Quantitative. & Setting: Unclear & Treatment Type: 1:1 & - Pre, post and follow up: Significant \\
Hiles & Case series. & Presenting difficulty: & Assessment: Adapted & differences between child's positivity*, eye \\
Howard, A. & & ASD, relationship & MIM scoring from McKay, & contact*, and acceptance of guidance* towards \\
R., & Pre/Post & difficulties & Pickens \& Stewart (1996), & parent. No significant difference between child's \\
Lindaman, & data, 3 & Sample Size: 8 parent- & parent/child sheets. & affect, proximity, responsivity, and task focus \\
S., & months follow & child dyads & Changes only monitored in & (p>.05). \\
Copeland, & up. & & session, not out of & - Significant differences in parent facial \\
R., \& Cross, & & session. & expression and affect
\end{tabular}


D. R. (2018)

USA
Inferential Age: Mean $=5.38$ years

$(\mathrm{SD}=1.92)$, Range 3-9

years.

Gender: Female $(n=6)$, male $(n=2)$.
Session No: 19

Frequency of sessions:

$2 \times 1$ hour daily for two

weeks (first day only one

session) cues $^{*}$, eye contact towards child ${ }^{*}$ and offering of

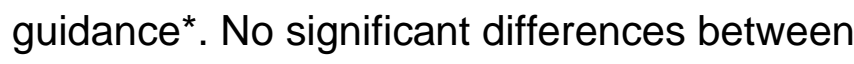

parent's positivity and proximity ( $p>.05)$.

- No differences within the dyad scale for social and balance $(p>.05)$.

-Time Points: Session 1-5 (time point 1), 6-10 (2), 11-16 (3) and 16-19 (4). Scores improved as sessions increased over time on parent domain* [including facial expression and affect*, encouragement ${ }^{\star}$, response to behavioural cues* and offering of guidance*] and child domain* [including positivity*, body positioning towards parent $^{\star}$, and acceptance of guidance ${ }^{\star}$. No significant differences were found between session numbers on the parent domain of 
proximity $(p>.05)$ and child domain of affect,

responsivity, and task focus ( $p>.05)$.

No exact $p$ values given. Unable to compute

effect sizes due to missing data.

\begin{tabular}{|c|c|c|c|c|}
\hline 4) & Quantitative. & Setting: School & Treatment Type: Group & -Mean scores within Theraplay TG significantly \\
\hline $\begin{array}{l}\text { Siu, A. F. Y. } \\
\text { (2009). }\end{array}$ & RCT. & $\begin{array}{l}\text { Presenting difficulty: } \\
\text { Internalising problems (t- }\end{array}$ & $\begin{array}{l}\text { Assessment: CBCL } \\
\text { (Achenbach et al., 2001) }\end{array}$ & $\begin{array}{l}\text { decreased post intervention** with large effect } \\
(d=1.19) \text {, compared with the CG. No exact } p\end{array}$ \\
\hline China & $\begin{array}{l}\text { Inferential } \\
\text { statistics. }\end{array}$ & $\begin{array}{l}\text { score above } 63 \text { on the } \\
\text { CBCL, Achenbach et al., } \\
2001) \text {. } \\
\text { Sample Size: } 46 \text { (TG = } \\
22, \mathrm{WC}=24) . \\
\text { Age: } T G: \text { Mean = } 7.84 \\
\text { (SD=1.32), WC: Mean = } \\
7.89(\mathrm{SD}=1.32) .\end{array}$ & $\begin{array}{l}\text { Session No: } 8 \text { sessions } \\
\text { Frequency of sessions: } \\
\text { Weekly, } 40 \text { minutes }\end{array}$ & values given. \\
\hline
\end{tabular}




\section{Gender: Female $(n=21)$,}

male $(n=25)$. TG: $56 \%$

female, WC: $54 \%$ female.

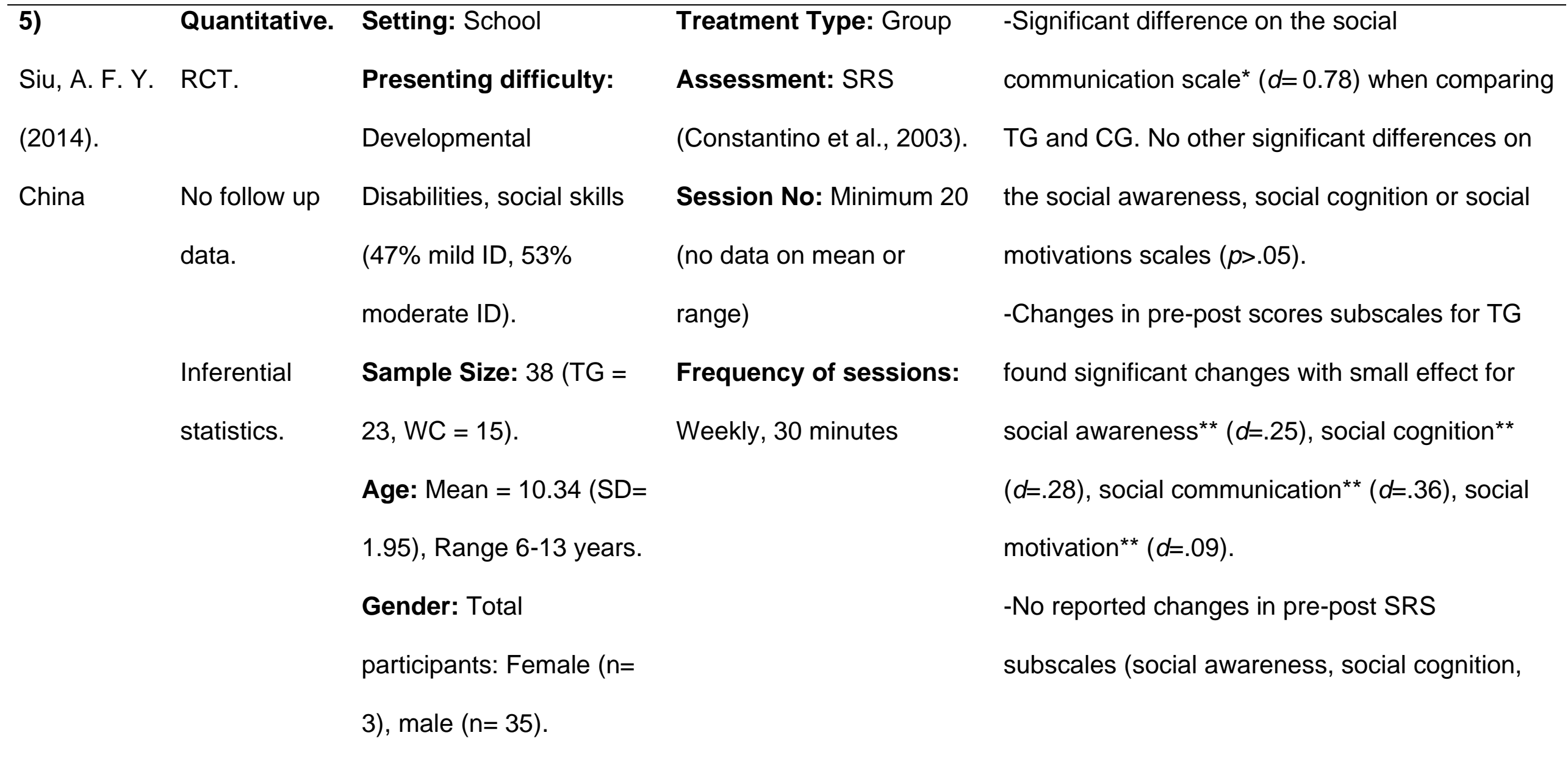


social communication and social motivation) for

the WC $(p>.05)$

\begin{tabular}{|c|c|c|c|c|}
\hline 6a) & Quantitative. & Setting: Medical centre, & Treatment Type: $1: 1$ & - Significant difference following Theraplay \\
\hline Wettig, $\mathrm{H}$. & Controlled & therapy rooms & Assessment: CASCAP-D & compared to control group at post-treatment, for \\
\hline H. G., & longitudinal & Presenting difficulty: & (Döpfner, Berner, & difficulties with attention ${ }^{* * *}(d=1.08)$, \\
\hline Coleman, & study (quasi- & Dual diagnosis of & Flechtner, Lehmkuhl \& & expressive $^{\star \star \star}(d=2.30)$ and receptive ${ }^{\star \star *}$ \\
\hline A. R., \& & experimental) & language disorder and & Steinhausen, 1999). & language problems $(d=1.83)$, cooperation* $(d=$ \\
\hline Geider, $\mathrm{F}$. & & shyness/social anxiety & Session No: Mean = 18, & $0.56)$ and being socially withdrawn* $(d=0.57)$. \\
\hline J. (2011). & Pre/post & (diagnosed by Speech & maximum 66 (no minimum & No significant differences for shyness, \\
\hline \multirow[t]{6}{*}{ Germany } & data, 2-year & Pathologist). & data). & conformity and mistrust were found ( $p>05)$. \\
\hline & follow up. & Sample Size: 52 (TG = & Frequency of sessions: & -TG: Significant difference post Theraplay in \\
\hline & & $22, C G=30)$ & Not reported, 30-45 & several areas including; shyness ${ }^{\star \star \star}(d=2.35)$, \\
\hline & Inferential & Age: $\mathrm{TG}:$ Mean $=4.1$ & minutes. & attention deficit ${ }^{\star *}(d=0.58)$, poor cooperation ${ }^{\star *}$ \\
\hline & statistics. & $(S D=1.1) . C G:$ Mean = & & ( $d=0.79)$, conformity ${ }^{* * *}(d=1.89)$, social \\
\hline & & 4.6 years $(S D=1.35)$. & & withdrawal $^{*}(d=0.77)$, mistrust ${ }^{*}(d=0.63)$, and \\
\hline
\end{tabular}


Gender: TG: Female

$(n=8)$, male $(n=14)$. receptive language problems ${ }^{\star *}(d=0.73)$. No

significant differences were found for low self-

confidence and expressive language problems

(p>.05).

- A significant change was also found between

pre and 2-year follow up for the above

difficulties, alongside a significant change in

expressive language disorder ${ }^{*}(d=1.10)$. There

continued to be no significant differences for low

self-confidence ( $p>$.05). Effect sizes ranged from

medium to large, with differences in mistrust

having the smallest effect $(d=0.63, p<.05)$, and

shyness the largest $(d=2.15, p<.001)$.

No exact $p$ values given. Effect sizes not

reported, calculated by researcher. 


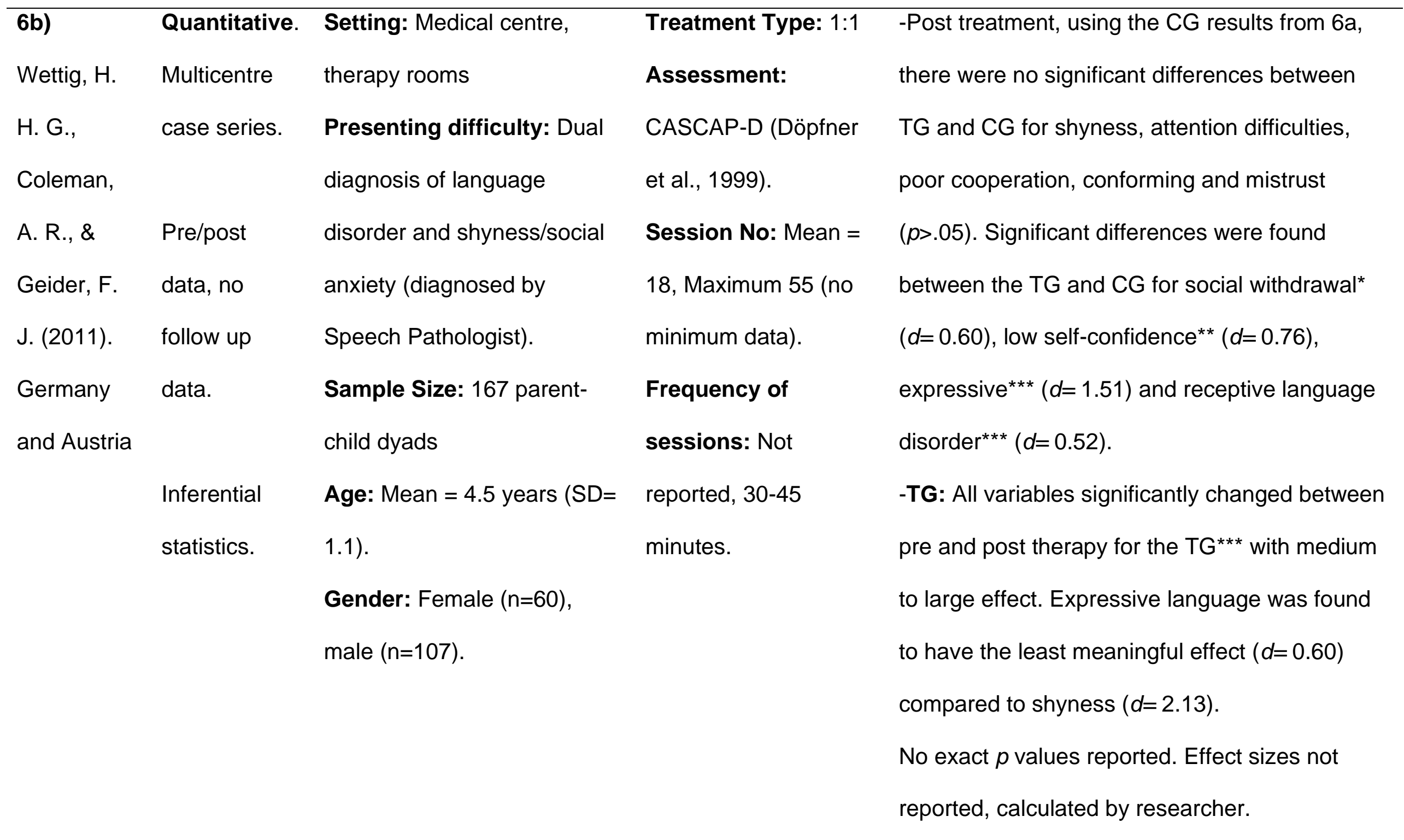


(6b) as the previously controlled study (6a).

Note: For quantitative studies the following significance indicators are used: ${ }^{*} p<.05 ;{ }^{\star *} p<.01 ;{ }^{* \star \star} p<.001$. All reported effect sizes were reported or have been converted to $d$ to facilitate comparisons, $d$ values indicate $d=0.2$ (small), 0.5 (medium), 0.8 (large), (Cohen, 1988).

1:1 Theraplay sessions typically involve one child, parent/carer and therapist. For studies with mixed methods, only quantitative data has been included. Article six has been split into two $(6 a, 6 b)$ as the same article describes two different studies.

MIMRS = Marschak Interaction Method Rating System; CBCL = Child Behavior Checklist; LAC = Looked after children; ID = Intellectual Disabilities, ASD = Autistic Spectrum Disorder; SDQ = Strengths and Difficulties Questionnaire; SRS = Social Responsiveness Scale; CASCAP-D = Clinical Assessment Scale for Child and Adolescent Psychopathology, TG = Treatment group; WC = Waitlist control, $C G=$ Control group . 
Table 3.

Quality Appraisal using Critical Appraisal Tool (Moola et al., 2017): Case series.

\begin{tabular}{|c|c|c|c|c|}
\hline Study & 1 & 2 & 3 & $6 b$ \\
\hline $\begin{array}{l}\text { Clear inclusion } \\
\text { criteria }\end{array}$ & $\mathrm{Y}$ & $\mathrm{N}$ & $\mathrm{N}$ & $U$ \\
\hline $\begin{array}{l}\text { Identification of } \\
\text { presenting problem } \\
\text { clear }\end{array}$ & $U$ & $U$ & $U$ & $U$ \\
\hline $\begin{array}{l}\text { Valid measure of } \\
\text { presenting } \\
\text { problem/specialist } \\
\text { service }\end{array}$ & $U$ & $\mathrm{~N}$ & $U$ & $Y$ \\
\hline $\begin{array}{l}\text { Consecutive } \\
\text { inclusion of } \\
\text { participants }\end{array}$ & $U$ & $\mathrm{~N}$ & $\mathrm{~N}$ & $\mathrm{~N}$ \\
\hline $\begin{array}{l}\text { Complete inclusion } \\
\text { of participants }\end{array}$ & $U$ & $\mathrm{~N}$ & $\mathrm{~N}$ & $\mathrm{~N}$ \\
\hline $\begin{array}{l}\text { Demographics } \\
\text { clearly reported }\end{array}$ & $U$ & $Y$ & $U$ & $Y$ \\
\hline $\begin{array}{l}\text { Clear description of } \\
\text { Theraplay }\end{array}$ & $\mathrm{N}$ & $Y$ & $U$ & $Y$ \\
\hline Therapist & U & $U$ & $\mathrm{Y}$ & $Y$ \\
\hline Theraplay trained & & & & \\
\hline
\end{tabular}


Standardised

U

U

$\mathrm{N}$

U

outcome measure

Theraplay four

Y

$\mathrm{N}$

$\mathrm{N}$

N

concepts measured

Outcomes/follow up U

$U$

U

Y

results reported

Appropriate

Y

Y

U

Y

statistical analysis

Presenting difficulty $U$

$U$

U

U

related to

Theraplay theory

Note: $\mathrm{Y}=\mathrm{Yes}, \mathrm{N}=\mathrm{No}, \mathrm{U}=$ Unclear

Yes, the study clearly provides a rich description of item; No, little information is provided to be able to adequately assess this item; Unclear, full or partial missing information, therefore unable to fully assess whether it addresses the item. 
Table 4.

Quality Appraisal using Critical Appraisal Tool (Tufanaru et al., 2017): Quasiexperimental designs.

\begin{tabular}{|c|c|}
\hline Study & $6 a$ \\
\hline Clear 'cause' and 'effect' & $\mathrm{Y}$ \\
\hline Valid measure of presenting problem/specialist service & Y \\
\hline Participants in comparison similar & $\mathrm{N}$ \\
\hline Participants in comparison receiving similar treatment & $\mathrm{N}$ \\
\hline Control group & U \\
\hline Demographics clearly reported & Y \\
\hline Clear description of Theraplay & Y \\
\hline Therapist Theraplay trained & Y \\
\hline Standardised outcome measure & U \\
\hline Theraplay four concepts measured & $\mathrm{N}$ \\
\hline Pre/post multiple measurements & $\mathrm{N}$ \\
\hline Follow up complete, or described/analysed & $U$ \\
\hline Same outcome measurements in comparison & $\mathrm{N}$ \\
\hline Appropriate statistical analysis & Y \\
\hline Presenting difficulty related to Theraplay theory & U \\
\hline
\end{tabular}

Note: $\mathrm{Y}=\mathrm{Yes}, \mathrm{N}=\mathrm{No}, \mathrm{U}=$ Unclear

Yes, the study clearly provides a rich description of item; No, little information is provided to be able to adequately assess this item; Unclear, full or partial missing information, therefore unable to fully assess whether it addresses the item. 
Table 5.

Quality Appraisal using Critical Appraisal Tool (Tufanaru et al., 2017): Randomised control trials (RCT).

\begin{tabular}{|c|c|c|}
\hline Study & 4 & 5 \\
\hline $\begin{array}{l}\text { Valid measure of presenting } \\
\text { problem/specialist service }\end{array}$ & $\mathrm{Y}$ & $\mathrm{Y}$ \\
\hline Demographics clearly reported & Y & U \\
\hline True randomisation & $U$ & U \\
\hline Treatment allocation concealed & U & U \\
\hline Groups similar at baseline & Y & U \\
\hline Participants blind to treatment & $U$ & U \\
\hline Clear description of Theraplay & $\mathrm{Y}$ & Y \\
\hline Therapist Theraplay trained & $\mathrm{Y}$ & U \\
\hline Groups treated identically & $\mathrm{N}$ & $\mathrm{N}$ \\
\hline Complete follow up & $U$ & U \\
\hline Standardised outcome measure & $\mathrm{Y}$ & Y \\
\hline Participants analysis in allocated groups & Y & Y \\
\hline Theraplay four concepts measured & $\mathrm{N}$ & $\mathrm{N}$ \\
\hline Outcomes measured in the same way & $U$ & Y \\
\hline Outcomes measured in reliable way & $U$ & $U$ \\
\hline Appropriate statistical analysis & Y & Y \\
\hline $\begin{array}{l}\text { Presenting difficulty related to Theraplay } \\
\text { theory }\end{array}$ & $U$ & $U$ \\
\hline
\end{tabular}

Note: $\mathrm{Y}=\mathrm{Yes}, \mathrm{N}=\mathrm{No}, \mathrm{U}=$ Unclear

Yes, the study clearly provides a rich description of item; No, little information is provided to be able to adequately assess this item; Unclear, full or partial missing information, therefore unable to fully assess whether it addresses the item. 


\section{Supplement}

Supplement A: Exclusion results from search

\begin{tabular}{|c|c|c|}
\hline \multicolumn{2}{|c|}{ Reason for Exclusion } & \multirow{2}{*}{$\begin{array}{c}\text { Number } \\
153\end{array}$} \\
\hline & Not in English & \\
\hline Not in & Books & 136 \\
\hline peer & Dissertations/Thesis & 38 \\
\hline reviewed & Abstracts & 3 \\
\hline \multirow[t]{12}{*}{ article } & Magazine & 8 \\
\hline & Films & 6 \\
\hline & Poster Presentations & 4 \\
\hline & Newspapers & 2 \\
\hline & Newsletters & 70 \\
\hline & Others (short course, question and answers script, & 3 \\
\hline & report) & \\
\hline & Before 1970 & 8 \\
\hline & Qualitative Article & 7 \\
\hline & No outcome measure/experimental design & 17 \\
\hline & Adult/Adolescent Population & 16 \\
\hline & Combination of Therapies & 9 \\
\hline Not using & Psychometric Assessment Design & 10 \\
\hline \multirow[t]{4}{*}{ Theraplay } & Other models (e.g. Play Therapy, Dyadic Developmental & 27 \\
\hline & Therapy, Filial Therapy) & \\
\hline & Inter Library Loans/Theraplay Institute Unable to find & 14 \\
\hline & Studies excluded following title/abstract review & 531 \\
\hline
\end{tabular}

